\title{
Driving aviation forward; Contrasting driving automation and aviation automation
}

Victoria A. Banks, Katherine L. Plant \& Neville A. Stanton

Technological solutions incorporating automated functionality have been seen as tools that can be used to reduce human error in both aviation and driving environments whilst bringing about improvements to operational safety and reduced accident rates. Historically, aviation has led the way but over recent years, developments in the field of driving automation have accelerated rapidly. This paper looks more closely at what aviation may now learn from driving by assessing the underlying motivations and use of automation within their respective fields, as well as the differing design philosophies used to implement such systems.

Keywords: aviation automation; vehicle automation; soft automation; hard automation; shared control; design philosophies

\section{Introduction}

The aviation industry has traditionally been at the forefront of technological innovation and engineering developments into the use of automated systems to improve the performance of human operators. In fact, driving automation has learnt many lessons from aviation. Stanton \& Marsden (1996) postulated that driving automation would yield similar problems to those found in aviation. Firstly, they anticipated that there would be shortfalls in potential benefits of automation in driving, that there would be problems with equipment reliability, issues relating to skill maintenance and training and finally, the design of systems themselves could lead to error. All of these expected issues appear to have come to fruition. However, with significant progress over recent 
Accepted for publication in Theoretical Issues in Ergonomics Science

years, it is possible that the aviation industry can now learn from developments in the field of driving automation. Since the early 2000's, automated technologies have saturated the marketplace with most new vehicles having some form of Advanced Driver Assistance System (ADAS) fitted at the point of sale. The main purpose of automated driving features, from a commercial point of view, is to continue the trend of safe, comfortable, efficient and enjoyable personal travel (Ward, 2000; Khan et al. 2012; Walker et al. 2001a). Historically, however, vehicle automation originates from the military whom recognised that highly automated vehicles could be used to gather intelligence, perform surveillance operations and for target acquisition and reconnaissance (Rouff \& Hinchey, 2011). At the same time, these vehicles could reduce the number of personnel required at ground level and thus reduce the number of fatalities in conflict. The Defence Advanced Research Project Agency (DARPA) has been instrumental in driving research and innovation into autonomous vehicles forward since the 1950's. A number of challenges have been set by DARPA in the pursuit of technological developments within this domain - specifically the Grand Challenges of 2004 and 2005 as well as an Urban Challenge in 2007. The Grand Challenges sought to demonstrate that autonomous vehicles could be used to undertake resupply missions in unfamiliar desert terrains and although no vehicles were able to complete the course in 2004, success was achieved in 2005. It was clear from this point on that unmanned vehicles could navigate itself across remote environments, on a variety of different road surfaces, and cope with different obstacles with limited or no global positioning satellites (Rouff \& Hinchey, 2011). The Urban Challenge in 2007 was designed to test the ability of autonomous vehicles to navigate safely and effectively through populated areas to simulate supply missions whilst adhering to normal driving laws. All vehicles that took part in the Urban Challenge had to be fitted with a form of E-Stop (essentially 
Accepted for publication in Theoretical Issues in Ergonomics Science

an Autonomous Emergency Brake). AEB uses radar and camera based technology to monitor and detect objects that enter the path of the vehicle (Banks et al. 2014). If a potential collision is detected, the system will alert the driver and autonomously trigger braking input in an attempt to minimise the speed at which a collision occurs. This addition of this technology was to ensure the safety of DARPA employees and spectators. These stipulations fuelled research and innovation within the automotive industry as the capabilities and promise that automated vehicles could improve the safety of our roads was recognised.

Of course, automated technologies operating at lower levels of functionality began entering the marketplace much earlier than the aforementioned DARPA challenges. Traditional automated systems, that automated operational components of vehicle control (e.g. automatic gearbox), first became available in the 1940's (Young et al. 2007). Since the 1990's, greater emphasis has been placed upon the automation of tactical and strategic aspects of driving (Walker et al. 2001b) which essentially carve the way forward towards driverless functionality - an aspiration of many (Reimer, 2014). Thus, whilst the concept of 'automation' is often used as a high level, catch-all concept, it differs dramatically between systems and domains.

In contrast to driving, automated solutions in aviation are used to assist the pilot in maintaining control of the aircraft. One of the core systems relating to cockpit automation is the Flight Management System (FMS). The FMS is used by pilots to assist them in flight planning, navigation, performance management and flight-progress monitoring activities (Sarter \& Woods, 1992). The first FMS was created in the mid 1970’s by Sperry Flight Systems and became part of the standard avionic suite for Boeing 757 and 767 aircraft in 1982 (Liden, 1994). By 1984, FMS became standard on both Airbus and Boeing aircraft. FMS represented a revolutionary step forward in the 
Accepted for publication in Theoretical Issues in Ergonomics Science

design of aircraft as it reduced workload significantly and led to a reduction in the number of flight crew required within the cockpit - from three to two. Of course, aviation automation has a much greater history. As with driving, automated solutions initially were designed to assist the pilot in the completion of physical tasks. For example, early Autopilot concepts were first engineered in the 1920's and 30’s which helped pilots keep the aircraft flying straight (Chialastri, 2012). During the 1960's, there was an influx of innovative design solutions to help enhance system safety including the development of automatic throttles (used to maintain a preset speed), flight directors (to help pilots achieve pre-selected targets) and navigation instruments. These all play a role in automating the more tactical and strategic aspects of flight operations.

It would appear then that automation within both the driving and aviation fields have taken the same evolutionary pathway as technologies become increasingly available and developed automating physical aspects of task first, before attempting the more cognitive elements of the task. However, the purpose of this paper is to compare and contrast aviation and driving automation in an effort to reveal any underlying differences in terms of motivation, implementation and human roles within the wider system. With driving automation arguably developing at a much faster rate, perhaps there are lessons that can be learned from this field and applied to aviation.

\section{Motivations for the use of automation}

Within aviation, both academics (e.g. Wiener, 1988) and regulatory bodies such as the Civil Aviation Authority (CAA; 2016) have provided insight into the motivations behind automation within the aviation environment (see Table 1). Whilst many of these factors remain relevant to driving automation, new motivations are also beginning to emerge. This is largely driven by the consumer marketplace and the realisation that automation can be used as a means to improve the overall driver experience within the 
Accepted for publication in Theoretical Issues in Ergonomics Science

vehicle. The Department for Transport (2015) report that on average, UK drivers spend around 235 hours a year behind the wheel which equates to approximately six working weeks. This means that automation paves the way for increased productivity by releasing the time available for drivers to engage in other non-driving related activities (e.g. Fagnant \& Kockelman, 2015). In addition, automation of the driving task can improve accessibility and meet the demands of our changing society (e.g. Alessandrini et al. 2015). That said, early automated interventions within the driving domain appear to mirror that of aviation (Stanton \& Marsden, 1996). Emphasis was initially placed upon safety systems. This was largely driven by the European New Car Assessment Programme (Euro NCAP) whom encouraged vehicle manufacturers to exceed the minimal safety requirements that were required by law. The aim was to provide potential new customers with transparent safety information via its internationally recognised Five Star Rating Scheme. It quickly became clear that the consumer marketplace could be influenced by such ratings and so, significant progress was made by vehicle manufacturers as they strived to achieve a Five Star rating. Since then however, less emphasis has been placed on 'safety' per se but more emphasis upon the commercialisation of products that can revolutionise and transform the driving experience. Whilst Elon Musk (CEO of Tesla Motors) claims that Autopilot can reduce the probability of having an accident by $50 \%$ which he quotes is “...twice as good as a person” (Musk, 2016), the very nature of the product has revolutionised the driving experience. 'Autopilot’ essentially automates both longitudinal and lateral control aspects enabling the vehicle to automatically control its speed, headway and lane position. Despite being a marker of "bad behaviour" during the intermediate phases of automation and therefore deemed a misuse of automation in its current form (e.g. Parasuraman \& Riley, 1997), Endsley (2017) revealed that Autopilot functionality 
Accepted for publication in Theoretical Issues in Ergonomics Science

generated additional time for the driver that could be used for texting whilst driving. With the need for driver intervention becoming increasingly marginal, there is theoretically no need for traditional steering or pedal arrangements. Mercedes (2015) have suggested that designs may move away from traditional vehicle interiors to ones that include steering wheels that can be stowed away or slide to the centre of the car, seats that can swivel or turn away from the steering wheel to enable face-to-face conversations with other passengers. The design of future "driver cockpits” is likely to be very different to what we are now used to (Casner et al. 2016; Diels \& Bos, 2016).

[Insert Table 1 here]

\section{Role of the human operator}

Before automation was introduced, both pilots and drivers would need to physically manipulate all controls and interpret and respond to cues within their environment to safely reach their destinations. Thus, they were active operators (Kaber \& Endsley 2004). Nowadays, much of the physical workload associated with task completion has been removed from the human operator and is now completed by automated subsystems (Banks et al. 2014). This essentially represents the automation of operational tasks (such as controlling speed and headway). Increasingly however, there is a trend towards the automation of tactical and strategic decision making processes within the transportation domain. These essentially represent higher level cognition such as responding to events (e.g. tactical task) and determining destinations (e.g. strategic task). Pilots and drivers alike find themselves monitoring the behaviour of automated subsystems but the responsibilities associated with each role differs tremendously. 
Accepted for publication in Theoretical Issues in Ergonomics Science

Typically, there are two pilots positioned within a commercial cockpit; a Pilot Flying (PF) and Pilot Monitor (PM). The Federal Aviation Administration (FAA) have formerly defined the roles and responsibilities of both PF and PM in their Safety Alert for Operators (SAFO 15011). However, in driving, no such formal definitions exist for a driver of an automated vehicle. Instead, Banks \& Stanton (2018) suggest that a driver can assume one of three possible roles throughout the duration of a journey; Driver Driving, Driver Monitor and Driver Not Driving. This is based upon the knowledge that both the level and type of automation can influence the role of the human operator within the control feedback loop (e.g. Banks et al. 2014). Levels of automation within driving have been formerly standardised by the Society of Automotive Engineers (SAE; J3016, 2016). Notably, these only provide functional definitions of technology rather than guidance of what the driver can and can not do. This means that the role of the driver is often left open to interpretation. This is problematic, particularly given that human operators continue to play a central role in system safety despite much of their work becoming automated. This calls into question the construct of automation.

The following models look more closely at the management structure underlying automation implementation within the aviation and driving domains (i.e. looking at the information sources available and the management of such resources). Figure 1a models the concept of automation within aviation based upon the work of Billings (1997) whilst Figure 1b models the concept of automation within driving. These do not appear vastly different. However, when discussed in reference to the trajectory of research and development within their respective domains, differences become clear.

[insert Figure 1a and $1 \mathrm{~b}$ about here] 
Accepted for publication in Theoretical Issues in Ergonomics Science

In 1997, Billings argued that the architecture of an automated system must be simple enough for the human operator to be capable of effectively managing it. The idea of command and control (e.g. Houghton et al. 2006) becomes particularly relevant here as Billings visualised the human operator as the head of authority. Figure 1a shows that pilots (both PF and PM roles) have access to a wide variety of informational resources that can be filtered and distributed via the management resource pool. The emphasis is very much upon keeping the human in-the-loop. Even during automated phases of flight, pilots have access to the information resource pool, as well as feedback via the FMS. Of course, this model is by no means fixed and may be reviewed in light of modern day developments. For example, whilst the construct of automation within aviation may not change dramatically if single crew operations become the norm, it is likely to change dramatically if 'pilotless' operations gain pace. With Boeing revealing that they plan to test pilotless planes in 2018, we could see the construct of automation becoming more in line with that of driving.

The construct of automation within driving reflects the trajectory of driving automation as posited by SAE whereby completely 'driverless' vehicles may occupy our roads in the future (Alessandrini et al. 2015). The construct of automation is therefore built upon the idea that the human operator will be removed entirely from the control-feedback loop. This means that much of the information available within the driving system will become embedded within the management resource pool. This means that not all of the information available within the 'information resources' pool will be shared with the driver and instead go directly to the automated subsystems located within the 'management resources' pool (Figure 1b). Only limited data is fed back to the driver - an effort only relevant to the intermediate phases of automation as a means to keep the driver involved in the control-feedback loop. Automated systems will 
Accepted for publication in Theoretical Issues in Ergonomics Science

have authority over the control resources pool, with intermittent driver access in the case of system malfunction or where operational limits have been reached during the intermediate levels of automation.

Of course, this construct has already proven to be problematic and it is not appropriate, or representative, of the intermediate levels of automation. Instead, the aviation construct shown in Figure 1a would be appropriate. However, we know that driver disengagement is a significant problem (e.g. Casner et al. 2016; Damböck et al., 2012; Eriksson et al. 2017; Stanton et al. 1997). We also know that the measures that have been put in place in an attempt to reduce driver disengagement have so far failed to deliver the desired behavioural outputs. For example, in order to avoid repeated warnings to place their hands on the steering wheel, some drivers have devised innovative solutions such as taping soda cans to the wheel, to simulate their hand inputs. Misuse and abuse of automation are therefore a real threat that can impact greatly upon overall system (Parasuraman \& Riley, 1997). Furthermore, driver monitoring and warning systems currently lack the sophistication required to effectively manage these instances of misuse and other out-of-the-loop performance problems. In the short term, these issues represent significant hurdles to successful implementation of partially automated driving solutions. However, jumping ahead to increased levels of automation (e.g. SAE Level 4 onwards) will not necessarily overcome these problems either. System failures remain an inevitable threat (Parasuraman et al. 1997). If mode errors still occur within a highly-trained and intensely regulated cohort of individuals that are exposed to prolonged periods of automation (i.e. within the aviation industry), we can assume these types of failures will also be experienced by drivers who do not receive any training in handling sophisticated technical devices (Stanton \& Young, 2005). 
Accepted for publication in Theoretical Issues in Ergonomics Science

\section{Design philosophies}

The original debate surrounding the use of different design philosophies relating to automation implementation came from the field of aviation as two leading market competitors adopted very different design approaches (soft versus hard automation). This led to questions about which approach was best.

‘Hard automation’ essentially prevents human error because the system can override human inputs (Young et al. 2007). In contrast, ‘soft automation’ can be overridden by the human operator. Whilst Airbus has been characterised as using the hard automation approach, by contrast Boeing has been characterised as using the soft approach. Both strategies use the same set of sensors and control devices but to very different ends (Young et al. 2007).

Driving on the other hand, uses a different approach. Whilst technologies such as Traction Control and Anti-Lock Braking Systems can be seen as examples of hard automation (they cannot be switched off and are always active), Adaptive Cruise Control is an example of 'soft automation' as the driver can choose to override it at any point. It is becoming clear, especially given the rise of 'combined function' technologies (National Highway Traffic and Safety Administration; NHTSA, 2013), that within driving automation, technologies can be both "soft" and "hard". Soft automation maintains the driver within the control-feedback loop (to some extent) enabling them to override autonomous function, whilst hard automation can override the control inputs of the driver (Kyriakidis et al. 2017). For example, at a basic level,

Lane Keeping Assist aims to prevent unintended lane deviations by gently 'nudging' the driver back into the boundaries of the lane markings. However, it can be overridden by the driver at any point and therefore representative of a 'soft' system. In contrast, the Autonomous Emergency Brake (AEB) system represents a form of hard automation 
Accepted for publication in Theoretical Issues in Ergonomics Science

within driving that will automatically trigger once time-to-collision thresholds have been met.

Of course, there is no evidence to suggest that one approach is more superior than the other although both Airbus and Boeing propose that their scheme is best (Hughes \& Dornheim, 1995). At closer inspection of the available data, it would appear that both approaches have inherent vulnerabilities of varying degrees across aircraft type, manufacturer and operator (FAA, 1996). Most automated-related accidents (i.e. those that are attributable to a mismatch between human and automated activities) occur on Airbus aircraft employing the hard approach (Young et al. 2007). However, there are more non-automated related accidents on Boeing aircraft (Young et al. 2007). Importantly, it would appear that regardless of the approach used, the literature indicates similar problems continue to plague the engineers and designers of autonomous transport systems in both aviation and driving domains. Common out-ofthe-loop performance problems continue to be implicated in human performance analysis. For example, automation can impact upon trust (Walker et al. 2016), susceptibility to complacency (Stanton, 2015), over- and under- load (Stanton et al. 1997; Young \& Stanton, 2002) and levels of situation awareness (Stanton et al. 2011). In aviation, these issues have been implicated in a number of high profile accident occurrences. On the $31^{\text {st }}$ May 2009, Air France Flight 447 (Airbus) stalled and crashed into the Atlantic Ocean killing all passengers and crew on board. A major investigation by the Bureau d'Enquêtes et-d'Analyses (2012) concluded that the accident occurred following the disconnection of Autopilot due to frozen pitot tubes in adverse weather. The findings scrutinize the aircrews lack of situation awareness and inability to establish and follow correct procedures. However, this has since been disputed by Salmon et al. (2016) who instead argue that it was a sociotechnical system 
Accepted for publication in Theoretical Issues in Ergonomics Science

failure whereby the crew, cockpit and aircraft systems all lost situation awareness. This signals a breakdown in communication between the crew and the systems on-board the aircraft.

On the $12^{\text {th }}$ February 2009, Continental Flight 3407 (Boeing) crashed near to Buffalo, New York killing all passengers and crew on board. A synopsis by the National Transportation Safety Board (2010) reported that the co-pilot had incorrectly programmed information into the on-board computers which caused the plane to slow down to an unsafe speed. This triggered a 'stall warning' but the captain did not notice that the plane was slowing down. Rather than pushing the control yoke forward (which would have been the correct procedure to follow), the pilot repeatedly pulled back on the controls which overrode two safety systems. The report concluded that there were no mechanical or structural problems that would have prevented resuming safe flight if the pilot had responded correctly to the original problem.

However, the true reality is that there are many other design philosophies relating to automation implementation. For example, the 'leftover principle’ (Hollnagel, 2003) and ‘compensatory principle’ (Fitts, 1951) offer alternative means of designing automation. However, within driving specifically, there is growing emphasis upon the concept of 'shared control', especially for the intermediate phases of automation whereby the driver is still expected to resume manual control of the vehicle in certain contexts. This essentially reflects the ideologies underpinning the complementarity principle whereby both the operator and system can work cooperatively throughout the duration of a task and appears particularly relevant to aviation (Wäfler et al. 2003).

\section{Leftover Principle}


Accepted for publication in Theoretical Issues in Ergonomics Science

The leftover principle is based upon the traditional view of 'fixed function allocation' whereby technology should be designed to do as much as possible (Hollnagel, 2003). In practice, this approach is not deemed suitable for complex sociotechnical systems. This is because it is often the 'easiest' tasks that are automated, leaving the more complex tasks for human operators (Bainbridge, 1983).

\section{Compensatory Principle}

The 'compensatory principle' is based on the idea that the capabilities and limitations of the human operator and automated system can be compared on a number of salient dimensions (see Fitts, 1951). Thus, rather than taking the traditional view of fixed function allocation, both operators and technologies can invoke changes to the level of automated support in real time (Dorneich et al. 2012; Rouse, 1976; Parasuraman et al. 1992). Fitts List (Fitts, 1951) marked the beginning of function allocation research (de Winter \& Dodou, 2014) and remains the most widely used function allocation technique (Older et al. 1997). It consists of eleven statements outlining which functions a human or machine can perform better at and therefore has become widely known for its MABA-MABA acronym ('Men are better at, Machines are better at'). However, the feasibility of this approach and its effect on operator performance is poorly understood (Parasuraman et al, 1992; Hoffman et al. 2002).

In order to be successful, there is a requirement for the human operator to understand the awareness, capabilities and limitations of any automated system in use with the same requirement on automated systems to understand the capabilities and limitations of the human operator at any given moment.

\section{Complementarity principle}


Accepted for publication in Theoretical Issues in Ergonomics Science

The concept of 'shared control' largely derives from the principle of ‘complementarity’ whereby both the operator and system can work cooperatively (Wäfler et al. 2003). This philosophy is based upon the idea that tasks can be allocated in a manner that can maintain overall control but can also provide a means to retain the operators skill (Grote et al. 1995; Hollnagel, 2003). For complex avionic and driving systems, task sharing is not restricted to common tasks or functions at only an operational level (Michon, 1985). Instead, tasks also need to be shared on both a tactical and strategic level of control (e.g. Michon, 1985, Abbink, 2006). For example, a drivers Autopilot system can automate longitudinal and lateral control aspects. It can also perform driver-initiated lane change manoeuvres automatically. However, the Autopilot system can prevent the driver from making a lane change if it deems the manoeuvre to be unsafe by overriding the control inputs of the driver. This command and control type relationship is analogous to a management infrastructure (Harris \& White, 1987) that enables the driver and automated system to communicate and behave cooperatively together in the interest of safety (Hoc et al. 2009). Conduct-by-Wire (Winner \& Hakuli, 2006) and H-Mode (Flemisch et al. 2003) are relevant design constructs for the development of cooperative guidance and control systems whereby both the driver and automated systems can influence the balance of control between different system agents (Flemisch et al. 2012). For example, the driver can choose to increase or decrease the level of automated control whilst the automated systems can recommend or suggest tasks that can be automated (Banks \& Stanton, 2017). The authors suggest that the shared control approach essentially views human operators and automated systems as a ‘unified system’ operating within a shared space.

Shared control is particularly relevant to both the intermediate phases of automation in driving but equally applicable to the field of aviation. This is because the 
Accepted for publication in Theoretical Issues in Ergonomics Science

human operator remains a critical agent within of the system hierarchy (e.g. Banks \& Stanton, 2016; Billings, 1997). However, there is limited literature available on shared control within the aviation domain (a notable exception includes Goodrich et al., 2008).

The shared control approach is based upon the requirement for operators to fully understand both the capabilities and limitations of the automated systems in use (i.e. systems must be transparent, reliable and predictable; Stanton \& Marsden, 1996). Clark \& Wilkes-Gibbs (1986) propose that successful collaboration between agents can only be achieved once common ground is established. To encourage the development of common ground between humans and systems (see Brennan \& Hulteen, 1995; Paek \& Horvitz, 1999), Brennan (1998) suggests that operators must receive feedback from systems to acknowledge that their inputs have been registered and also that systems must notify operators when errors occur. This will help encourage the development of appropriate and accurate mental models relating to system function (Norman, 1983).

However, 'shared control' approaches are far from perfect and numerous design challenges remain. For example, the first fatal incident involving the use of a more sophisticated automated driving feature occurred in May 2016. This incident involved a Tesla Model S being operated in 'Autopilot' mode - meaning that both longitudinal and lateral control aspects were automated simultaneously. NHTSA (2017) commissioned an investigation following the incident and concluded that the accident was a result of “driver error”. NHTSA cited that a 'prolonged period of distraction' was the likely cause given that the drivers hands were only detected for 25 seconds of the 37 minute journey. Whilst this accident differs from those in aviation, given the drivers complete lack of response to a hazardous situation, it does signal that automated systems operating under the guise of 'shared control' do not eliminate issues relating to over- 
Accepted for publication in Theoretical Issues in Ergonomics Science

trust and complacency (Banks et al. 2018; Parasuraman et al. 1993; Lee and See, 2004; Stanton, 2015; Walker et al. 2016; Young and Stanton, 2002).

\section{Discussion and conclusions}

Going forward, this paper highlights some of the similarities and differences between aviation and driving automation. It indicates that whilst the underlying motivations for using automation in the aviation and driving domains are similar, the construct of automation (i.e. the vision of automation going forward) and the underlying design philosophies used to develop such systems do differ to some extent. This is further summarised in Table 2 and shows that whilst aviation typically favours 'soft' and 'hard' design approaches, the driving field utilises a more distributed view of control (i.e. 'shared control') in recognition that fully 'driverless' function is some way off. Thus, the construct of automation in driving is now becoming more aligned to that in aviation. The traditional view of automation in driving was that automated functionality would completely automate the task and that the driver would essentially become a 'Passenger'. However, the intermediate phases of automation dictate that the driver still needs to remain within the management structure and therefore should still hold a 'Managerial' role to some extent. In order to address this shift in view, there is now increasing interest in utilising a 'shared control' design philosophy within the driving domain. The authors posit that this approach is also relevant to the field of aviation and suggest that the industry may benefit from recent innovations and developments surrounding ‘shared control’ systems within driving. The key to success appears to lie within how well system capabilities and limitations are understood. Whilst this is relatively simple for fixed allocation of function approaches (e.g. principles underlying the left-over principle), this becomes increasingly difficult for more complex sociotechnical systems involving multiple system agents and remains an 
Accepted for publication in Theoretical Issues in Ergonomics Science

enduring challenge for systems designers and engineers going forward. The authors suggest that this essentially represents a "challenge of relationships" between the human operator and automated systems. Kyriakidis et al. (2017) suggest that new forms of training and certification will be extremely important to encourage the development of shared control within driving. As it currently stands, drivers receive no formal training about the capabilities and limits of the automated systems available within their vehicles. Importantly, informing operators about the underlying design philosophies used to develop automated systems in the first place could be beneficial regardless of domain (e.g. Tarnowsk, 1999). Further training will help operators learn how and when to use automated technologies to their gain (Parasuraman \& Riley, 1997). This appropriate utilisation of technology will enable operators to develop appropriate mental models relating to system function and therefore its limits (Plant \& Stanton, 2012; Reimer, 2014).

[insert Table 2 about here]

\section{Acknowledgements}

This project was co-funded by Innovate UK, the UK's Innovation Agency, with support from the UK Aerospace Technology Institute.

References

Abbink, David A. "Neuromuscular analysis of haptic gas pedal feedback during car following." (2006). 
Accepted for publication in Theoretical Issues in Ergonomics Science

Alessandrini, Adriano, Andrea Campagna, Paolo Delle Site, Francesco Filippi, and Luca Persia. "Automated vehicles and the rethinking of mobility and cities." Transportation Research Procedia 5 (2015): 145-160.

Allwood, Jens, Joakim Nivre, and Elisabeth Ahlsén. "On the semantics and pragmatics of linguistic feedback." Journal of semantics 9, no. 1 (1992): 1-26.

Bainbridge, L. (1983). Ironies of automation. Automatica, 19(6), 775-779.

Banks, Victoria A., Katherine L. Plant and Neville A. Stanton. "Driver error or designer error: Using the Perceptual Cycle Model to explore the circumstances surrounding the fatal Tesla crash on 7th May 2016”. Safety Science.

Banks, Victoria A., and Neville A. Stanton. "Driver-centred vehicle automation: Using network analysis for agent-based modelling of the driver in highly automated driving systems. Ergonomics 59, no. 11 (2016): 1442-1452.

Banks, Victoria A., and Neville A. Stanton. “Automobile automation: Distributed Cognition on the road. CRC Press (2017).

Banks, Victoria A., and Neville A. Stanton. “Analysis of driver roles: Modelling the changing role of the driver in automated driving systems using EAST.” Theoretical Issues in Ergonomics Science, DOI: 10.1080/1463922X.2017.1305465. (2018).

Banks, Victoria A., Neville A. Stanton, and Catherine Harvey. "Sub-systems on the road to vehicle automation: Hands and feet free but not 'mind'free driving." Safety Science 62 (2014): 505-514.

Brennan, Susan E. "The grounding problem in conversations with and through computers." Social and cognitive approaches to interpersonal communication (1998): 201-225. 
Accepted for publication in Theoretical Issues in Ergonomics Science

Brennan, Susan E., and Eric A. Hulteen. "Interaction and feedback in a spoken language system: A theoretical framework." Knowledge-based systems 8, no. 2-3 (1995): 143-151.

Bureau d'Enquêtes et-d'Analyses. "Final report on the accident on $1^{\text {st }}$ June 2009 to the Airbus A330-203 registered F-GZCP operated by Air France flight AF 447 Rio de Janeiro - Paris.” (2012). Available at: https://www.bea.aero/docspa/2009/fcp090601.en/pdf/f-cp090601.en.pdf. Accessed 7 August 2017.

Billings, C. E. (1991). "Human-centred aircraft automation: A concept and guidelines.” (1991). https://ntrs.nasa.gov/archive/nasa/casi.ntrs.nasa.gov/19910022821.pdf

Casner, Stephen M., Edwin L. Hutchins, and Don Norman. "The challenges of partially automated driving." Communications of the ACM 59, no. 5 (2016): 70-77.

Chialastri, Antonio. "Automation in aviation." In Automation. InTech, 2012.

Civil Aviation Authority. “ATM Automation: Guidance on human-technology integration.” (2016). Available at: http://publicapps.caa.co.uk/CAP1377. [Accessed 18.07.2017].

Clark, Herbert H., and Deanna Wilkes-Gibbs. "Referring as a collaborative process." Cognition 22, no. 1 (1986): 1-39.

Damböck, D., K. Bengler, M. Farid, and L. Tönert. "Übernahmezeiten beim hochautomatisierten Fahren." Tagung Fahrerassistenz. München 15 (2012): 16. Department for Transport. 2015. “The Pathway to Driverless Cars: Summary Report and Action Plan 2015.” Accessed September 192016. https://www.gov.uk/government/uploads/system/uploads/attachmentçdata/file/4 01562/pathway-driverless-cars-summary.pdf .

Diels, Cyriel, and Jelte E. Bos. "Self-driving carsickness." Applied ergonomics 53 (2016): 374-382. 
Accepted for publication in Theoretical Issues in Ergonomics Science

Dorneich, Michael C., Patricia May Ververs, Santosh Mathan, Stephen Whitlow, and Caroline C. Hayes. "Considering etiquette in the design of an adaptive system." Journal of Cognitive Engineering and Decision Making 6, no. 2 (2012): 243265.

Endsley, Mica R. "Autonomous Driving Systems: A Preliminary Naturalistic Study of the Tesla Model S." Journal of Cognitive Engineering and Decision Making (2017): 1555343417695197.

Eriksson, A., Petermeijer, S. M., Zimmerman, M., De Winter, J. C. F., Bengler, K. J., \& Stanton, N. A. (2017). Rolling out the red (and green) carpet: supporting driver decision making in automation to manual transitions. IEEE Transactions.

Eriksson, Alexander, V. A. Banks, and N. A. Stanton. "Transition to manual: comparing simulator with on-road control transitions." Accident Analysis \& Prevention 102 (2017): 227-234.

Eriksson, Alexander, and Neville A. Stanton. "Takeover Time in Highly Automated Vehicles: Noncritical Transitions to and From Manual Control." Human factors 59, no. 4 (2017): 689-705.

Fagnant, Daniel J., and Kara Kockelman. "Preparing a nation for autonomous vehicles: 1 opportunities, barriers and policy recommendations for 2 capitalizing on selfdriven vehicles 3." Transp. Res 20 (2014).

Federal Aviation Administration. (1996). “Human Factor Team Report on The interfaces between flightcrews and modern flight deck systems.” (1996).

Federal Aviation Administration. "Safety Alert for Operators SAFO 15011 2015.” Available at: http://www.faa.gov/other_visit/aviation_industry/airline_operators/airline_safety /safo. Accessed 7 August 2017. 
Accepted for publication in Theoretical Issues in Ergonomics Science

Fitts, Paul M. "Human engineering for an effective air-navigation and traffic-control system." (1951).

Flemisch, Frank O., Catherine A. Adams, Sheila R. Conway, Ken H. Goodrich, Michael T. Palmer, and Paul C. Schutte. "The H-Metaphor as a guideline for vehicle automation and interaction." (2003).

Flemisch, Frank, Matthias Heesen, Tobias Hesse, Johann Kelsch, Anna Schieben, and Johannes Beller. "Towards a dynamic balance between humans and automation: authority, ability, responsibility and control in shared and cooperative control situations." Cognition, Technology \& Work 14, no. 1 (2012): 3-18.

Foyle, David C., Robert S. McCann, and Stephen G. Shelden. "Attentional issues with superimposed symbology: Formats for scene-linked displays." In Proceedings of the Eighth international symposium on Aviation Psychology, vol. 98, p. 103. 1995.

Goodall, Noah. "Ethical decision making during automated vehicle crashes." Transportation Research Record: Journal of the Transportation Research Board 2424 (2014): 58-65.

Goodrich, Kenneth H., Paul C. Schutte, and Ralph A. Williams. "Piloted evaluation of the H-mode, a variable autonomy control system, in motion-based simulation." In AIAA Proceedings, pp. 1-15. 2008.

Harris, C J, and I White. "Advances in commond, control and communication systems.” London: Peregrinus (1987).

Hoffman, Robert R., Paul J. Feltovich, Kenneth M. Ford, and David D. Woods. "A rose by any other name... would probably be given an acronym." IEEE Intelligent Systems 17, no. 4 (2002): 72-80. 
Accepted for publication in Theoretical Issues in Ergonomics Science

Hollnagel, Erik. "The role of Automation in joint cognitive systems." IFAC Proceedings Volumes 36, no. 22 (2003): 9-11.

Houghton, Robert J., Chris Baber, Richard McMaster, Neville A. Stanton, Paul Salmon, Rebecca Stewart, and Guy Walker. "Command and control in emergency services operations: a social network analysis." Ergonomics 49, no. 12-13 (2006): 1204-1225.

Hughes, D. and Dornheim, M. A. “Accidents direct focus on cockpit automation.” Aviation Week and Space Technology 1, (1995): 52-54.

Kaber, David B., and Mica R. Endsley. "The effects of level of automation and adaptive automation on human performance, situation awareness and workload in a dynamic control task." Theoretical Issues in Ergonomics Science 5, no. 2 (2004): 113-153.

Khan, Ata M., Ataur Bacchus, and Stephen Erwin. "Policy challenges of increasing automation in driving." IATSS research 35, no. 2 (2012): 79-89.

Kyriakidis, Miltos, Joost CF de Winter, Neville Stanton, Thierry Bellet, Bart van Arem, Karel Brookhuis, Marieke H. Martens et al. "A human factors perspective on automated driving." Theoretical Issues in Ergonomics Science (2017): 1-27.

Lee, John D., and Katrina A. See. "Trust in automation: Designing for appropriate reliance." Human factors 46, no. 1 (2004): 50-80.

Liden, Sam. "The evolution of flight management systems." In Digital Avionics Systems Conference, 1994. 13th DASC., AIAA/IEEE, pp. 157-169. IEEE, 1994.

Lu, Zhenji, Riender Happee, Christopher DD Cabrall, Miltos Kyriakidis, and Joost CF de Winter. "Human factors of transitions in automated driving: A general framework and literature survey." Transportation research part F: traffic psychology and behaviour 43 (2016): 183-198. 
Accepted for publication in Theoretical Issues in Ergonomics Science

Mercedes. "The long haul truck of the future.” (2015). Available at:

https://www.mercedes-benz.com/en/mercedes-benz/innovation/the-long-haultruck-of-the-future/. Accessed 10.05.2016.

Michon, John A. "A critical view of driver behavior models: What do we know, what should we do." Human Behavior and Traffic Safety (1985): 485-520.Musk, Elon. “2016 Interview at ‘Future Transport Solutions’ conference in Oslo (21 April 2016). Quote at 22 minutes, 36 seconds.” Available at https://youtube/HaJAF4tQVbA?t=1341 (retrieved on 7 August 2017).

National Highway Traffic Safety Administration. "Preliminary Statement of Policy Concerning Automated Vehicles.” (2013).

National Highway Traffic Safety Administration. “ODI Resume 2017.” Available at https://static.nhtsa.gov/odi/inv/2016/INCLA-PE16007-7876.PDF

National Transportation Safety Board. "Loss of control on approach Colgan Air, Inc. Operating as Continental Connection Flight 3407 (Report NTSB-AAR-10-01).” Washington, DC. (2010).

Nees, Michael A., and Bruce N. Walker. "Auditory displays for in-vehicle technologies." Reviews of human factors and ergonomics 7, no. 1 (2011): 58-99.

Norman, Donald A. "Some observations on mental models." Mental models 7, no. 112 (1983): 7-14.

Older, Melanie T., Patrick E. Waterson, and Chris W. Clegg. "A critical assessment of task allocation methods and their applicability." Ergonomics 40, no. 2 (1997): 151-171.

Parasuraman, Raja, Peter A. Hancock, and O. Olofinboba. "Alarm effectiveness in driver-centred collision-warning systems." Ergonomics 40, no. 3 (1997): 390399. 
Accepted for publication in Theoretical Issues in Ergonomics Science

Parasuraman, Raja, Robert Molloy, and Indramani L. Singh. "Performance consequences of automation-induced'complacency'." The International Journal of Aviation Psychology 3, no. 1 (1993): 1-23.

Parasuraman, Raja, and Victor Riley. "Humans and automation: Use, misuse, disuse, abuse." Human factors 39, no. 2 (1997): 230-253.

Parasuraman, Raja, Toufik Bahri, John E. Deaton, Jeffrey G. Morrison, and Michael Barnes. Theory and design of adaptive automation in aviation systems. Catholoc Univ of America Washington DC Cognitive Science Lab, 1992.

Paek, Tim, and Eric Horvitz. "Uncertainty, utility, and misunderstanding: A decisiontheoretic perspective on grounding in conversational systems." In AAAI Fall Symposium on Psychological Models of Communication, North. 1999.

Plant, Katherine L., and Neville A. Stanton. "Why did the pilots shut down the wrong engine? Explaining errors in context using Schema Theory and the Perceptual Cycle Model." Safety science 50, no. 2 (2012): 300-315.

Reimer, Bryan. "Driver assistance systems and the transition to automated vehicles: A path to increase older adult safety and mobility?." Public Policy \& Aging Report 24, no. 1 (2014): 27-31.

Rouff, Christopher, and Mike Hinchey, eds. Experience from the DARPA urban challenge. Springer Science \& Business Media, 2011.

Rouse, William B. "Adaptive allocation of decision making responsibility between supervisor and computer." In Monitoring behavior and supervisory control, pp. 295-306. Springer US, 1976.

Salmon, Paul M., Guy H. Walker, and Neville A. Stanton. "Pilot error versus sociotechnical systems failure: a distributed situation awareness analysis of Air France 447." Theoretical Issues in Ergonomics Science 17, no. 1 (2016): 64-79. 
Accepted for publication in Theoretical Issues in Ergonomics Science

Sarter, Nadine B., and David D. Woods. "Pilot interaction with cockpit automation: Operational experiences with the flight management system." The International Journal of Aviation Psychology 2, no. 4 (1992): 303-321.

Sarter, Nadine B., and David D. Woods. "Pilot interaction with cockpit automation II: An experimental study of pilots' model and awareness of the flight management system." The International Journal of Aviation Psychology 4, no. 1 (1994): 1-28.

Shladover, S. E. “The truth about "self-driving” cars.” Scientific American, 314 no. 6, (2016): 52-57.

Society for Automotive Engineers. “Taxonomy and Definitions for Terms Related to On-Road Motor Vehicle Automated Driving Systems.” (2015). Accessed October 12 2015. http://standards.sae.org/j3016ç201401/.

Stanton, Neville A. “Responses to Autonomous Vehicles.” Ingenia, 9, (2015).

Stanton, Neville A., Alain Dunoyer, and Adam Leatherland. "Detection of new in-path targets by drivers using Stop \& Go Adaptive Cruise Control." Applied ergonomics 42, no. 4 (2011): 592-601.

Stanton, Neville A, and Judy Edworthy. Human factors in auditory warnings. Ashgate, 1999.

Stanton, Neville A., and Philip Marsden. "From fly-by-wire to drive-by-wire: safety implications of automation in vehicles." Safety Science 24, no. 1 (1996): 35-49.

Stanton, Neville A., and Mark S. Young. "Driver behaviour with adaptive cruise control." Ergonomics 48, no. 10 (2005): 1294-1313.

Stanton, Neville A., Mark S. Young, and B. McCaulder. "Drive-by-wire: the case of mental workload and the ability of the driver to reclaim control." Safety Science 27, no. 2-3 (1997): 149-159. 
Accepted for publication in Theoretical Issues in Ergonomics Science

Tarnowsk, Etienne. "Understanding design philosophy can help pilots benefit from modern automated flight systems." ICAO Journal 54, no. 09 (1999): 22-24.

Walker, Guy H., Neville A. Stanton, and Paul Salmon. "Trust in vehicle technology." International journal of vehicle design 70, no. 2 (2016): 157-182.

Walker, Guy H., Neville A. Stanton, and Mark S. Young. "Where is computing driving cars?." International Journal of Human-Computer Interaction 13, no. 2 (2001): 203-229.

Walker, Guy H., Neville A. Stanton, and Mark S. Young. "Hierarchical Task Analysis of Driving: A New Research Tool.” In M. A. Hanson (Ed.), Annual Conference of the Ergonomics Society, (2001b): 435-440.

Ward, Nicholas J. "Automation of task processes: An example of intelligent transportation systems." Human Factors and Ergonomics in Manufacturing \& Service Industries 10, no. 4 (2000): 395-408.

Wiener, Earl L. “Cockpit automation.” Human Factors in Aviation, (1988): 433-461.

Winner, Hermann, and Stephan Hakuli. "Conduct-by-wire-following a new paradigm for driving into the future." In Proceedings of FISITA world automotive congress, vol. 22, p. 27. 2006.

de Winter, Joost CF, and Dimitra Dodou. "Why the Fitts list has persisted throughout the history of function allocation." Cognition, Technology \& Work 16, no. 1 (2014): 1-11.

Young, Mark S., and Neville A. Stanton. "Malleable attentional resources theory: a new explanation for the effects of mental underload on performance." Human factors 44, no. 3 (2002): 365-375. 
Accepted for publication in Theoretical Issues in Ergonomics Science

Young, Mark S., Neville A. Stanton, and Don Harris. "Driving automation: learning from aviation about design philosophies." International Journal of Vehicle Design 45, no. 3 (2007): 323-338. 
Accepted for publication in Theoretical Issues in Ergonomics Science

Table 1. Motivations behind automation implementation within aviation and driving domains

\begin{tabular}{|l|l|}
\hline \multicolumn{1}{|c|}{ Aviation Automation } & \multicolumn{1}{c|}{ Driving Automation } \\
\hline Improves safety & Improves safety \\
Increases capacity & Improves mobility \\
Improves security & Eases congestion \\
Increased passenger comfort & Increases capacity \\
Maintenance costs & Releases time for the driver \\
Workload reduction & Improves driver experience \\
Reduces fuel consumption & Increased comfort \\
Operational flexibility & \\
Reduces training costs & \\
\hline
\end{tabular}


Accepted for publication in Theoretical Issues in Ergonomics Science

Table 2. Contrasting aviation with driving automation

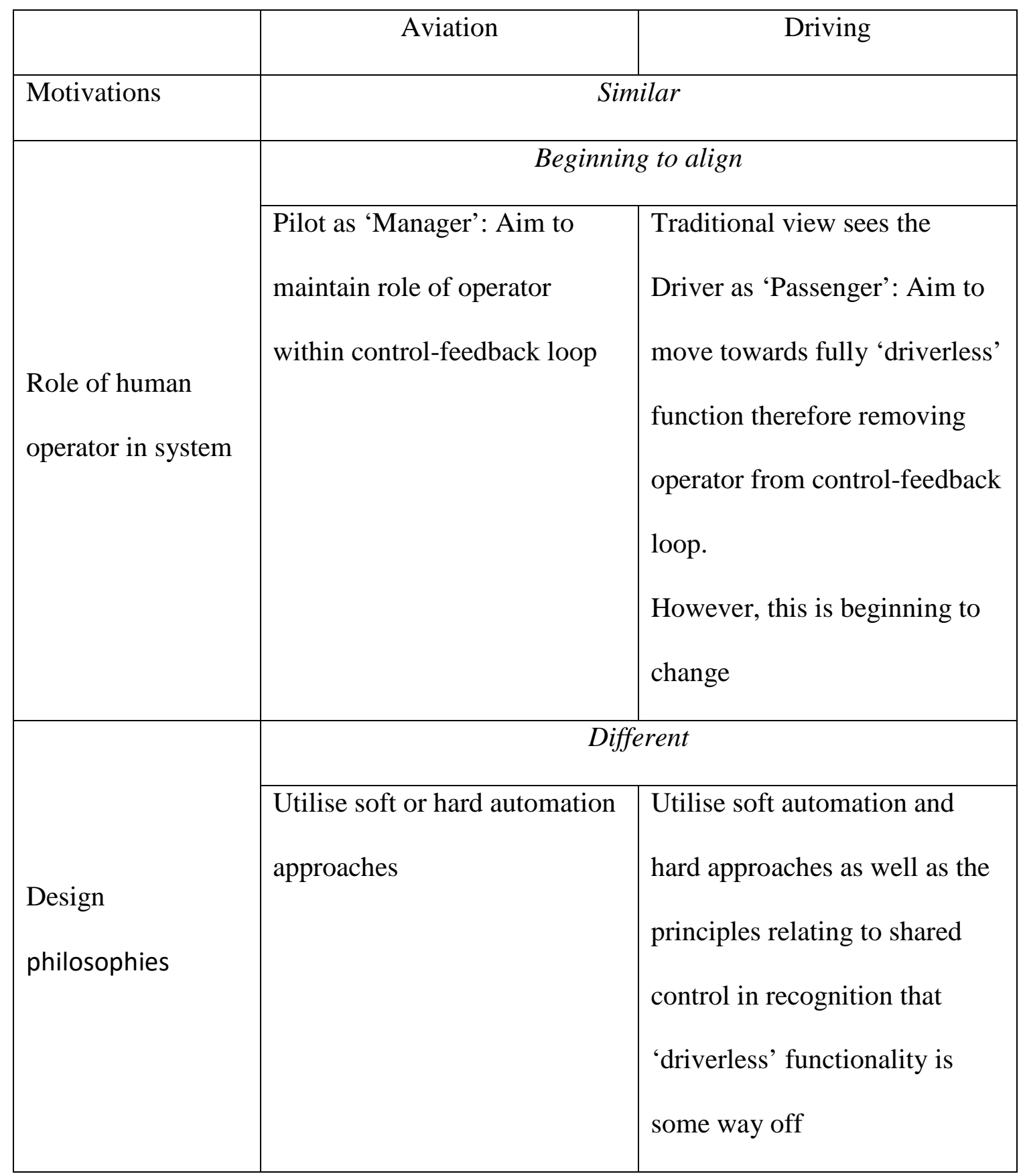


Accepted for publication in Theoretical Issues in Ergonomics Science

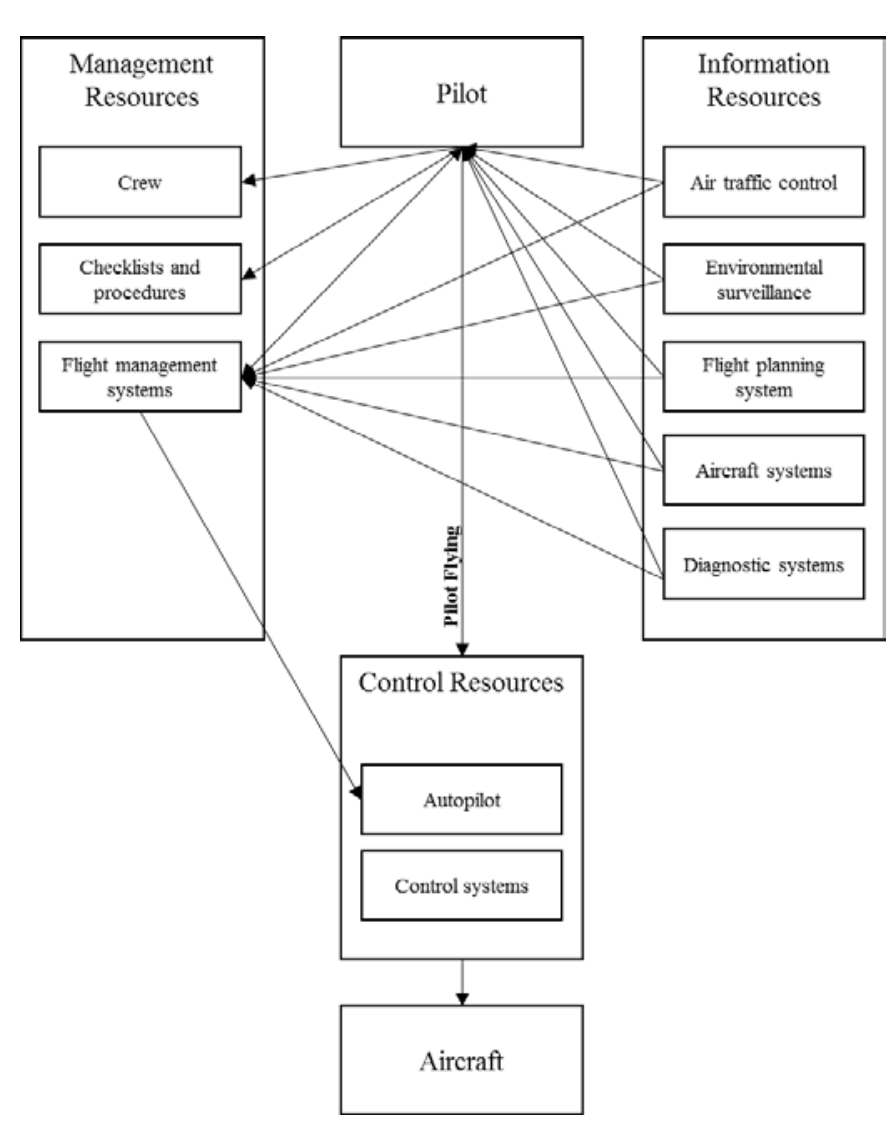

(a)

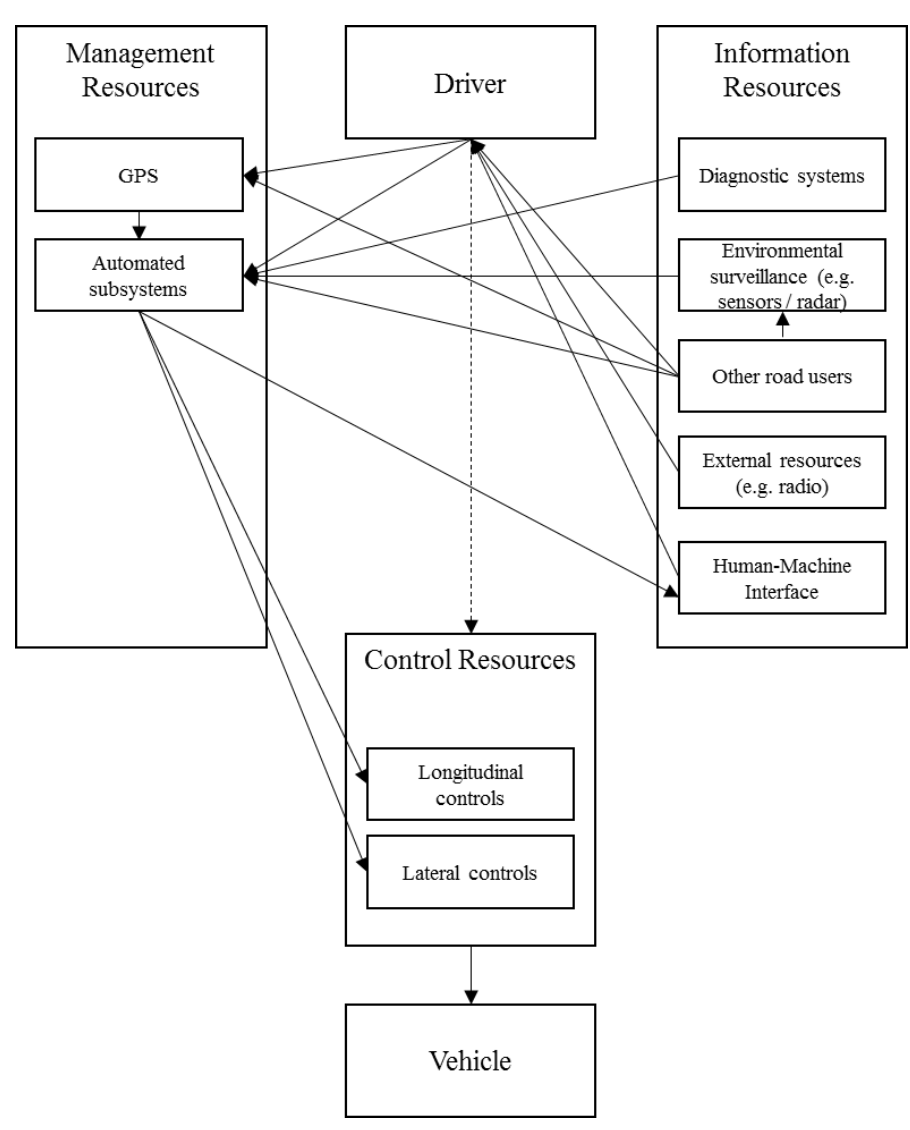

(b)

Figure 1a. Construct of aviation automation (adapted from Billings, 1997). Figure 1b. Construct of driving automation. Note dashed line represents intermittent access to control resources during the intermediate phase of automation 